\title{
Valorização das construções pessoais apresentadas pelos estudantes acerca do tema bactéria: uma investigação no ensino de ciências
}

\author{
Recovery of personal constructions presented by students about the \\ theme bacterium: a research in science education
}

\author{
${ }^{1}$ Wanderley Pivatto Brum ufsc2013@yahoo.com.br \\ ${ }^{1}$ Sani de Carvalho Rutz da Silva sani@utfpr.edu.br
}

\section{RESUMO}

A identificação das concepções alternativas dos estudantes é importante, pois são entendidas como produtos dos esforços imaginativos das crianças para descrever e explicar o mundo físico que as rodeiam. Tais concepções devem ser encaradas como construções pessoais, que o professor tem o dever de procurar conhecer, compreender, e valorizar para decidir o que fazer e como fazer o seu ensino, ao longo do estudo de um tópico. Tendo isto por base, este trabalho buscou identificar as concepções alternativas de estudantes do $6^{\circ}$ ano de uma escola da rede pública de Florianópolis, Santa Catarina sobre o tema: bactérias. A pesquisa tem caráter qualitativo e o instrumento para coleta de dados consiste de um questionário. Os resultados apontaram que o cotidiano e a mídia influenciam fortemente em suas concepções. Esse trabalho serve de referência para futuros estudos na tentativa de contribuir para a melhoria do ensino de ciências, em especial de microbiologia.

Palavras-chave: Bactéria; Ensino de ciências; Concepções alternativas; Saúde humana.

\begin{abstract}
The identification of alternative conceptions of students is important because they are seen as products of children's imaginative efforts to describe and explain the physical world around them. These concepts should be regarded as personal constructions, the teacher has the duty to know, understand, and value to decide what to do and how to do your teaching through the study of a topic. Having it based on this work was to identify alternative conceptions of students of the 6th year in a public school in Florianópolis, Santa Catarina on the topic: bacteria. The research is qualitative and the instrument for data collection consists of a questionnaire. The results showed that the daily and the media strongly influence in their conceptions. This work serves as a reference for future studies aiming to contribute to the improvement of science education, especially microbiology.
\end{abstract}

Keywords: Bacteria; Science Education; Alternative conceptions; human Health.

1 Universidade Tecnológica Federal do Paraná - UTFPR. Campus Ponta Grossa - Av. Monteiro Lobato, Km 04, CEP: 84.016-210 - Ponta Grossa - PR - Brasil. 


\section{INTRODUÇÃO}

Os primeiros momentos da criança na escola a colocam diante de novos desafios e experiências que terão reflexos no seu desenvolvimento afetivo, cognitivo e social. De certa forma, reconhece que há muito a se conhecer e, por isso, formula perguntas e demonstra curiosidade acerca de um fato. Carletto e Viecheneski (2013) entendem que as crianças quando inseridas nos primeiros anos da escolarização, demonstram grande curiosidade, embora ao observá-las e ouvi-las, é possível apontar evidencias a partir de suas explicações sobre os fenômenos do cotidiano, e nessas tentativas, suas hipóteses e idiossincrasias de explicar os acontecimentos do cotidiano.

Nesse contexto, o papel do professor na promoção da aprendizagem é desafiar os conceitos já aprendidos pelos estudantes para que se reconstruam mais ampliados e consistentes, tornando-se assim mais inclusivos com relação a novos conceitos. Quanto mais elaborado e enriquecido é um conceito, maior possibilidade ele tem de servir de parâmetro para a construção de novos conceitos. Saviani (2003) defende que professor e estudantes se encontram numa relação de ensino, cujo objetivo é de estudar os conhecimentos acumulados historicamente pelo estudante, a fim de construir e aprimorar novas elaborações do conhecimento.

O professor deve estar ciente de que não basta tratar somente de conteúdos atuais em sala de aula, mas sim, também, resgatar conhecimentos mais amplos e históricos, para que os estudantes possam interpretar suas experiências e suas aprendizagens na vida social. Sob essa perspectiva, a importância do ensino de Ciências para crianças hoje é reconhecida em todo o mundo, em grande parte em virtude das recentes descobertas no campo do estudo das concepções construídas pelas crianças.

Suas ideias e concepções sobre o mundo que as rodeia são construídas ao longo dos anos do ensino fundamental, independentemente do fato de as crianças serem ensinadas formalmente ou não. Para Saviani (2003), não ensinar ciências nessa idade significa ignorar esse processo, abandonando a criança a seus próprios pensamentos, privando-a de um contato mais sistematizado com a realidade e de poder trocar pontos de vista com seus pares.

Conforme apontamentos dos Parâmetros Curriculares Nacionais: Ciências Naturais (PCN), é de suma importância superar a postura "cientificista” que o ensino de Ciências apresentou por muito tempo. O objetivo fundamental do ensino de Ciências passou a ser o de dar condições para o estudante identificar problemas a partir de observações sobre um fato, levantar hipóteses, testá-las, refutá-las e abandoná-las quando fosse o caso, trabalhando de forma a tirar conclusões sozinho (Brasil, 1998). Para que o ensino e aprendizagem sejam realizados de forma significativa faz-se necessário considerar os conhecimentos do estudante, do professor e da Ciência. Desta maneira, são valorizados os conhecimentos prévios dos estudantes, sua vivência, sua cultura e o senso comum. Também são valorizados os conhecimentos científicos do professor e sua didática atrelada com as concepções do campo de conhecimento científico em conjunto com as teorias científicas da Ciência.

Neste trabalho, o foco é o ensino de bactéria, uma vez que possuem importantes aplicações práticas, como na indústria farmacêutica, na indústria de alimentos, na ecologia, na saúde humana, etc. O objetivo deste estudo foi identificar as concepções alternativas de estudantes de ensino fundamental sobre bactérias e sua relação com a saúde humana. O intuito é identificar fatores que possam vir a contribuir na proposição de novas estratégias pedagógicas para o ensino em ciências.

\section{As concepções alternativas}

Pesquisas na área do ensino de ciências têm demonstrado que as concepções alternativas dos estudantes são de grande importância para o processo de ensino e aprendizagem de ciências (CARVALHO; BOSSOLAN, 2009). Neste processo, as concepções alternativas são entendidas como produtos dos esforços imaginativos das crianças para descrever e explicar o mundo físico que as rodeiam. 
Estas são representações que cada indivíduo faz do mundo que o rodeiam, consoante a sua própria maneira de ver o mundo e de ver a si próprio. As concepções, para Paiva e Martins (2013), devem ser encaradas como construções pessoais, que o professor tem o dever de procurar conhecer, compreender, e valorizar para decidir o que fazer e como fazer o seu ensino, ao longo do estudo de um tópico. Estas concepções são construídas pelos estudantes e a partir do nascimento o acompanham também em sala de aula, onde os conceitos científicos são inseridos sistematicamente no processo de ensino e aprendizagem (MENINO; CORREIA, 2005).

O conhecimento das concepções alternativas dos estudantes é fato de grande importância para o planejamento das atividades pedagógicas, e também no processo de ensino e aprendizagem das ciências. Estas concepções assumem o papel central, porque todo o trabalho realizado na aula deve fazer-se de tal modo que os estudantes sejam estimulados a apresentar, questionar, testar as suas ideias, para que as mesmas sejam desenvolvidas ao invés de constituírem barreira à aprendizagem (MENINO; CORREIA, 2005).

O fato é que diversas pesquisas em educação têm se preocupado com a análise das concepções alternativas dos estudantes, uma vez que a aprendizagem escolar é influenciada pelo que o estudante já sabe, e principalmente, pelo fato das concepções alternativas não coincidirem com o cientificamente aceito (AUSUBEL, 2003). Na perspectiva construtivista, concepções ou significados não podem ser transferidos do professor para os estudantes, mas são construídos pelos próprios estudantes de um jeito que faça sentido para eles (KATTMANN, 2001).

O aprendizado em ciências das crianças é em parte influenciado por ideias pessoais e entendimento que constroem sobre o mundo (SHEPARDSON, 2002). As crianças apresentam explicações para os animais (ex: uma lagarta forma um casulo porque precisa de uma casa para viver) e tendem a classificar os animais de acordo com suas estruturas ou função biológica (animais que voam).

Razões humanas (SHEPARDSON, 2002) que as crianças relacionam com aves reflete-se no fato de incorporar atributos humanos nesses animais (ex. o pica-pau tira pequenos insetos das árvores porque eles são médicos das árvores). O pensamento teológico (SHEPARDSON, 2002) das crianças sobre aves incorpora a noção que elas migram não por causa de escassez de alimento, mas, as aves estão ameaçadas devido às baixas temperaturas (ex. as aves migram porque podem congelar) (PROKOP, 2007).

Em relação à classificação taxonômica dos animais, Kattmann (2001) mostra que a maioria das crianças classifica os animais de acordo com o habitat e locomoção. Prokop (2007) também relata a dificuldade que as crianças têm em classificar aves, principalmente quando se compara aves com animais parecidos com aves.

Quanto aos artrópodes, as crianças indicam como insetos as minhocas, as centopeias e as aranhas. Associam esses animais com habitat abaixo do solo, com plantas, abaixo de troncos e pedras, e outros habitats característicos (SHEPARDSON, 2002). Também observou que o conhecimento das crianças em relação ao ciclo dos insetos se resume às experiências que as crianças têm com borboletas e mariposas no seu dia-a-dia. A maioria afirma que o ciclo das borboletas/ mariposas consiste em três estágios: lagarta - pupa - adulto. As crianças não identificam o estágio de ovo no ciclo desses insetos, mostrando um entendimento.

Mortimer (2000) acredita que o ensino efetivo em sala de aula depende também de um elemento facilitador representado pelo professor. Neste caso, o professor propicia aos estudantes situações sobre o conteúdo que possam utilizar suas concepções alternativas. O professor pode sugerir uma situação problema relacionada com a realidade dos estudantes, com o intuito de fazer com que busquem em suas concepções alternativas, respostas para tal problema. Este fato permite um maior incentivo na caminhada conjunta entre teoria e prática e, ao mesmo tempo, entre o real e o imaginário.

O levantamento desses conhecimentos também pode ser feito a partir de questionários montados pelo professor, os quais ajudarão os próprios estudantes a conhecerem suas próprias concepções e, isso consequente- 
mente, auxiliará na elaboração das atividades em sala de aula. Esse tipo de atividade pode propiciar discussões entre os estudantes, favorecendo a interação entre as concepções alternativas.

A utilização da aula teórica deverá ser baseada na interação ou mediação do professor. Neste tipo de estratégia adotada (aula teórica), Ausubel (2003) defende o ensino por transmissão de conhecimento. Acredita que os estudantes não apresentam estruturação na cognição para que possam “descobrir” os conceitos científicos.

Ao defender a transmissão de conhecimento entre professor e estudante em sala de aula, Ausubel (2003) se refere ao processo de ensino pela aprendizagem receptiva significativa. Este tipo de aprendizagem, por meio da aula expositiva, preconiza a integração de diferentes assuntos, se o professor e/ou os recursos didáticos disponíveis evidenciarem as semelhanças e diferenças entre o novo conceito e as concepções alternativas de cada estudante. A maioria do tema que o estudante aprendeu na aula teórica é reforçado com a aula prática, esta pode possuir atividades que também envolvam o seu cotidiano, facilitando assim, a sua aprendizagem.

\section{PROCEDIMENTO METODOLÓGICO}

A pesquisa, de abordagem qualitativa, foi realizada com uma turma de 25 estudantes do $6^{\circ}$ ano do ensino fundamental de uma escola da rede pública da cidade de Florianópolis, Santa Catarina. Os estudantes, no ato da pesquisa, ainda não haviam estudado o tema: bactéria. Para coleta de dados, foi utilizado um questionário contendo duas questões abertas que teve como intuito, descobrir as concepções alternativas dos estudantes sobre o tema bactéria e sua implicação na saúde humana. A análise de conteúdo a posteriori foi escolhida para extrair os significados explícitos e implícitos nas respostas apresentadas pelos estudantes. Segundo Bardin (2002), a possibilidade de uma categorização com categorias a posteriori é possível a partir da análise do material.

As questões apresentadas no questionário foram as seguintes:

1. Pedro reclamava de dor de dente e pediu a sua mãe para levá-lo ao dentista. O dentista diagnosticou que Pedro estava com muitas cáries, as quais provocavam muita dor. A maneira correta de evitá-las seria uma melhor escovação, afirmou o dentista, o que ele não fez. Responda:

a. O que existe na boca de Pedro que provocou as cáries?

b. Por que a boa escovação teria evitado as cáries?

2. Agora, pense que você seja uma bactéria causadora de uma doença. Escreva: que tipo de doença você causaria nas pessoas?

\section{RESULTADOS E DISCUSSÕES}

Com relação a pergunta 1, item a, que trata sobre o que existe na boca de Pedro que provocou cáries, a opção por vermes aparece como categoria mais citada, mostrando uma fragilidade sobre o conceito de vermes e micro-organismos. Estes dados são sustentados pelos estudos de Simonneaux (2000), no qual os estudantes pesquisados mostram-se confusos quanto à diferenciação entre bactérias e demais micro-organismos. No entanto, relembra Paiva e Martins (2005), que estas confusões conceituais devem ser encaradas como construções pessoais e que o professor tem o dever de procurar conhecer, compreender e valorizar, com o objetivo de direcionar seus ensinamentos. Os resultados encontram-se agrupados no quadro 1. 
Quadro 1: Concepções alternativas dos estudantes com relação a questão 1, item a.

\begin{tabular}{|c|c|}
\hline O que provocou a cárie em Pedro & Resultados percentuais \\
\hline Vermes & $45 \%$ \\
\hline Bactéria & $15 \%$ \\
\hline Vírus & $23 \%$ \\
\hline Comida estragada & $10 \%$ \\
\hline Péssima escovação & $7 \%$ \\
\hline Total & $100 \%$ \\
\hline
\end{tabular}

Assim como em trabalho desenvolvido por Bizerra et al (2009), muitos estudantes acreditam que os vermes provocam cáries, atribuindo-lhes um valor negativo. No caso deste estudo, quase metade das respostas fornecidas pelos estudantes evidenciavam aspectos a doenças envolvendo vermes. Em contrapartida, um ponto positivo que pode ser observado em relação as possíveis causas de cáries é que alguns estudantes foram capazes de reconhecer que as bactérias são organismos que podem causar a cárie, sem que isso seja uma regra geral para todas as bactérias. Isso demonstra que, apesar da existência de concepções alternativas, alguns estudantes apresentam conhecimentos que são iguais aos validados cientificamente.

Com relação a questão 1 , item b, que trata sobre a qualidade de uma boa escovação na tentativa de evitar cáries, os estudantes apontaram: a) tira a sujeira da boca; b) o flúor que possui a pasta elimina os vermes; c) mantém os dentes brancos e limpos. Essas categorias (figura 1) apontam como o cotidiano e a mídia influenciam na construção de concepções das pessoas sobre determinado tema.

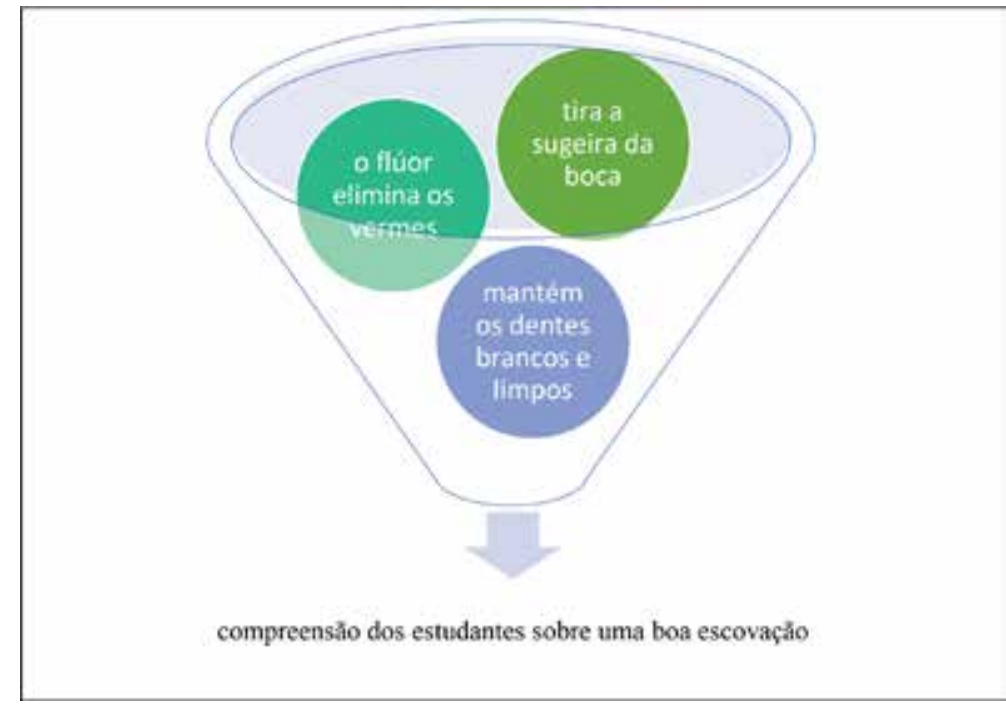

Figura 1: concepções dos estudantes sobre a importância de uma boa escovação.

Com relação a categoria "tirar a sujeira da boca”, Kattmann (2001) cita a importância de considerar os aspectos culturais da vida da pessoa, que desde os tempos primórdios, o homem buscava a evolução da vida, procurando alívio para os seus males adotando práticas de acordo com suas crenças.

Essas experiências encontram-se pautadas no campo empírico, ou seja, dos fatos já ocorridos por meio da vivência própria ou dos aconselhamentos de amigos e familiares. Quando esses estudantes apontam a boa escovação com o intuito de tirar a sujeira da boca, Mortimer (2000) enfatiza que essas concepções se alojam em modelos explicativos, que consideram tais experiências ao largo da lógico científica e da medicina convencional. 
Essas concepções criam uma percepção em torno das origens de certas crendices, justificada muitas vezes pelo modo de ditar o comportamento, criando a alusão quanto à origem das suas próprias concepções. Bizerra et al (2009) relembram que é preciso respeitar as concepções alternativas das pessoas, permitindo um espaço de troca de experiências, expectativas, certezas e valores. Para os autores, existem pessoas que não se adequam ou não aceitam passivamente os tratamentos prescritos, onde medicações alopatas exige o estreitamento do conhecimento sobre o indivíduo e a sua dinâmica de vida.

Com relação a categoria “mantém os dentes brancos e limpos”, os estudantes que optaram por esta resposta, apontam a preocupação com a estética dos dentes, imagem fortemente vivenciada nos meios de comunicação.

Shepardson (2002) em seu estudo, enfatiza que os conhecimentos ao longo do crescimento da criança serão construídos com base nas ideias tanto do meio familiar, quanto nas vivências com grupos de amigos, admitindo que em nossa cultura, é muito possível que atrelem conhecimentos aprendidos também por meio da televisão e da internet, o que tem pouco aprofundamento científico.

Barbosa e Borges (2006) ainda relatam que esse pouco aprofundamento existente na aprendizagem é reforçado quando livros, professores, a mídia impressa e a televisão também abordam o conceito de forma superficial, enfatizando mais os aspectos estético do que a possível explicação do conceito.

De certa maneira, essa categoria leva a acreditar que as concepções alternativas dos estudantes são reforçadas por agentes internos como professores ou externos como a televisão e também observada nos livros como resultado do fato que ainda não temos informações mais específicas do que seja realmente uma bactéria.

Com relação a categoria “o flúor elimina os vermes”, Barbosa e Borges (2006) identificam isso como problema pelo fato desta concepção mostrar que o estudante não tem uma compreensão do significado de verme. Mortimer (2000) reforça que a noção que o estudante apresenta sobre verme pode em muito atrapalhar a compreensão de que a bactéria, por ser muito importante para a vida do ser humano, seja lembrada apenas como doença.

No entanto, relembra Shepardson (2002), da importância de se inserir discussões sobre o tema bactéria e sua relação com a vida humana na escola básica, primeiramente por se tratar de um assunto que se insere em meio às problemáticas tanto ambientais como a saúde humana. Em um segundo momento, a importância da temática se justifica pelo fato dela ser cheia de possibilidades para o ensino, por entrelaçar diversos conteúdos.

Com relação a questão 2, um maior número de estudantes apontou a gripe como doença que provocaria nas pessoas (quadro 2). Também notamos uma dificuldade de alguns estudantes em diferenciar doenças provocadas por bactérias, vermes e vírus, que segundo Barbosa e Borges (2006), isso se deve ao fato de que é mais fácil para o estudante conceituar algo que pode ser visto, do que explicar o funcionamento ou a importância de algo que não se vê.

\section{Quadro 2: Qual Doença Causaria?}

\begin{tabular}{|c|c|}
\hline Categorias & Quantidade \\
\hline Gripe & 10 \\
\hline Micose & 3 \\
\hline Verminose & 3 \\
\hline Vômitos & 5 \\
\hline Dor de cabeça & 2 \\
\hline Febre & 2 \\
\hline
\end{tabular}


A gripe e o vômito aparecem como doenças mais citadas (60\%) pelos estudantes investigados. Os dados confirmam o fato de que muitos não diferenciam doença, agente causador e sintomas. Para Bolander (2004), embora doença esteja relacionado como um distúrbio das funções de um órgão, da psique ou do organismo como um todo que está associado a sinais e sintomas específicos, é um conceito complexo e multifacetado. Por exemplo, no senso comum, a palavra tem em linguagem cotidiana diferentes significados, como muitas vezes distintos do significado científico. Surós (2005) relembra por outro lado que sintoma é qualquer alteração da percepção normal que uma pessoa tem de seu próprio corpo, do seu metabolismo, de suas sensações, podendo ou não consistir-se em um indício de doença. Sintomas são frequentemente confundidos com sinais, que são as alterações percebidas ou medidas por outra pessoa, geralmente um profissional de saúde.

Há uma evidente dificuldade dos estudantes em identificarem as doenças causadas por bactérias. Bolander (2004) enfatiza que bactérias são sensíveis aos antibióticos, estes quando usados sob prescrição médica, constituem uma excelente arma contra doenças bacterianas. Essas doenças são transmitidas por gotículas de saliva (tuberculose, lepra, difteria, coqueluche), por contato com alimento ou objeto contaminado (disenteria bacilar, tétano, tracoma) ou por contato sexual (gonorreia, síflis). A essa dificuldade, Carlétti (2007) afirma que o número de doenças causadas por micro-organismos vem aumentando significativamente.

Nessa perspectiva, os conhecimentos que os estudantes apresentam sobre tratamento de doenças bacterianas (e que correspondem aos conceitos cientificamente validados) são fundamentais para a futura sensibilização da comunidade para as problemáticas envolvendo enfermidades causadas por esses organismos. No entanto, uma boa higiene depende também da educação que é dada às crianças e jovens de hoje. Por isso, em muitas escolas a higiene tem sido um tema abordado com os alunos para que estes possam compreender que a saúde é um direito de todos e uma parte fundamental do crescimento e desenvolvimento do ser humano.

\section{CONSIDERAÇÕES FINAIS}

Diante dos resultados obtidos com a pesquisa, observa-se que há a necessidade do professor utilizar estratégias de ensino que possam identificar as concepções alternativas dos estudantes para planejar atividades de aprendizagem que possam estabelecer relações significativas entre as concepções dos estudantes e o conhecimento científico.

Reeve e Bell (2009) destacam que o mais importante e necessário para o objetivo geral de promover a saúde nas crianças é conectar esse conhecimento sobre saúde das crianças com um entendimento do que motive seus comportamentos e práticas atuais. No entanto, muitos currículos atuais não têm considerado o modo de pensar das crianças sobre saúde e evidenciam a incapacidade de compreensão das crianças sobre tal assunto.

A instrução sobre saúde deve ir além dos tópicos cuja importância tem sido determinada pelos adultos e envolve as crianças mais ativamente quando examinando e desenvolvendo suas próprias ideias (CARRASCOSA, 2005). Ainda com relação aos resultados, esses sugerem que os estudantes participantes da pesquisa apresentaram conhecimentos sobre micro-organismos, especificamente no caso das bactérias. A maioria deles compreende que são microscópicos e se relacionam com o ser humano. As concepções dos estudantes se relacionam com o seu cotidiano, recebendo forte influência dos meios de comunicação e do conhecimento adquirido pelo meio escolar. As bactérias foram reconhecidas como seres relacionados a doenças. Esse fato intensifica a influência do cotidiano para o conhecimento científico desenvolvido pela estrutura cognitiva dos estudantes.

Com base nos resultados obtidos, é importante que o professor reconheça a influência da mídia, tendo em vista que as explicações que são fornecidas pelos estudantes apresentam certa coerência com determinados aspectos relativos ao conteúdo validado cientificamente. Além disso, as respostas dos estudantes são suficientes 
para que eles sejam capazes de entender o que é divulgado atualmente pela mídia, mesmo que seus conceitos sejam confusos e apresentem alguns equívocos (LIBANORE, 2007).

Nesse contexto, o trabalho configura-se como ponto de reflexão para a prática docente, especialmente para a microbiologia, que apresenta aspectos que podem prejudicar a aprendizagem. As concepções podem ser tanto um obstáculo quanto um ponto de partida para a compreensão do assunto. O levantamento das ideias prévias deve ser usado como ferramenta inicial no processo de ensino e aprendizagem, pois fornece condições para que o professor identifique o que o estudante já conhece e trabalhe a partir desses conceitos.

Esse trabalho caracteriza-se como ponto de partida para a elaboração de ferramentas para que possam vir a auxiliar o professor em seu fazer docente, como consequência promovendo um aprendizado mais significativo para o estudante. Além disso, almeja-se encontrar pontos que possam servir de base para que seja realizada a proposição de novas maneiras de se ensinar o assunto em questão.

\section{REFERÊNCIAS}

AUSUBEL, D.P. Aquisição e retenção de conhecimentos: Uma perspectiva cognitiva Editora Plátano, 2003.

BARBOSA, J.P.V; BORGES, A.T. O entendimento dos estudantes sobre energia no início do ensino médio, 2006. Dissertação (Mestrado) - UFMG, Belo Horizonte.

BARDIN, L. Análise de Conteúdo. Lisboa: Edições 70, 2002.

BIZERRA, A. et al. Crianças pequenas e seus conhecimentos sobre microrganismos. In: ENCONTRO NACIONAL EM PESQUISA EM EDUCAÇÃO EM CIÊNCIAS, 7, 2009, Florianópolis. Anais... Belo Horizonte: ABRAPEC, 2009. Disponível em <http://www.foco.fae.ufmg.br/pdfs/472.pdf> Acesso em 20 out. 2013.

BOLANDER, V.B. Enfermagem fundamental: abordagem psicofisiológica. Lisboa: Lusodidacta, 2004.

BRASIL. Secretaria de Educação Fundamental. Parâmetros Curriculares Nacionais: terceiro e quarto ciclos do ensino fundamental; Ciências. Brasília: MEC/SEF, v. 4, 1998. Disponível em: <http/portal.mec.gov.br/seb/ arquivos/pdf/ciencias.pdf.> Acesso em 22 out. 2014.

CARLÉTTI, D. S. Concepções dos alunos sobre microbiologia. In: ENCONTRO NACIONAL DE ENSINO DE BIOLOGIA, 2., 2007, Uberlândia. Anais... Uberlândia: Sbenbio, 2007. CD-ROM.

CARLETTO, M.R.; VIECHENESKI, J.P. Iniciação à alfabetização científica nos anos iniciais: contribuições de uma sequência didática. Investigações em Ensino de Ciências. v18, pp. 525-543, 2013.

CARRASCOSA, J. El problema de las concepciones alternativas en la actualidade (Parte I). Análisis sobre las causas que la originan y/o mantienen. Revista Eureka sobre Enseñanza e Divulgación de las Ciencias, Cádiz, v. 2, n. 2, p. 183-208, 2005. Disponível em <http://www.apac-revista/Volumen2/Carrascosa_2005A.pdf>. Acesso em 19 set. 2013.

CARRASCOSA, J., PEREZ, D.; VALDÉS, P. Como ativar a aprendizagem significativa conceitos e teorias? Santiago: OREALC / UNESCO, 2005.

CARVALHO, J.C.; BOSSOLAN, N.R.S. Algumas concepções dos alunos do ensino médio a respeito de proteínas. VII Encontro Nacional de Pesquisa em Educação em Ciências, Florianópolis, 2009. 
KATTMAN, U. Aquatics, Flyers, Creepers and Terrestrials - students' conceptions of animal classification. Journal of Biological Education. n. 35, 2001.

LESSA, D. B. et al. Como se "pega” gripe? Um estudo das concepções alternativas de estudantes sobre sistema imunológico. In: ENCONTRO NACIONAL DE ENSINO DE QUÍMICA, 14. 2009, Curitiba. Anais... Curitiba: UFPR/DQ, 2009. Disponível em <http://www.quimica.ufpr.br/eduquim/eneq2008/resumos/R0676-1. pdf $>$ Acesso em 20 out. 2013.

LIBANORE, A. C. L. As concepções alternativas de alunos da $8^{a}$ série do ensino fundamental sobre o fenómeno do efeito estufa. Maringá: Universidade Estadual de Maringá, 2007. 145f. Dissertação (Mestrado). Programa de Pós-Graduação em Educação para a Ciência e o Ensino de Matemática, Maringá, 2007.

MENINO, H.L.; CORREIA, S.O. Concepções alternativas idéias das crianças acerca do sistema reprodutor humano e reprodução. Educação \& Comunicação, n. 4, p. 97-117, s.d, 2005.

MORTIMER, E. F. Pressupostos epistemológicos para uma metodologia de ensino de química: mudança conceitual e perfil epistemológico. Química Nova, v. 15, n. 3, p. 242-249, 2000.

OLIVEIRA, S. S. Concepções alternativas e ensino de biologia: como utilizar estratégias diferenciadas na formação inicial de licenciados. Curitiba: UFPR. Educar, n. 26, p. 233-250, 2005.

PAIVA, A.L.B.; MARTINS, C. M. C. Concepções prévias de alunos de terceiro ano do Ensino Médio a respeito de temas na área de Genética. Disponível: <http://www.fae.ufmg.br/ensaio/vol7especial/artigopaivaemartins. pdf > Acesso em: 20 out. 2013.

PROKOP, P. Why Do Cocks Crow? Children's concepts About Birds. Res Sci Educ. 2007.

REEVE, S; BELL, P. Children's Self-documentation and Understanding of the Concepts 'Healthy' and 'Unhealthy'. International Journal of Science Education. Volume 31, September, 2009.

SAVIANI, D. Escola e Democracia. 36ª ed. Campinas: Autores Associados, 2003.

SHEPARDSON, D. Bugs, butterflies, and spiders: children's understandings about insects. Int. J. Sci. Educ., Vol. 24, N. 6, 627-643. 2002.

SIMONEAUX, L. A study of pupils conceptions and reasoning in connection with micrpbes, as a contribution to research in biotecnology education. International Journal of Science Education. vol 22, no 6, 2000.

SURÓS, J. Semiologia Médica e Técnica Exploratória. São Paulo: Guanabara koogan, 2005. 